\title{
LUT
}

University

\section{Civic Data Literacies for Bottom-up Data Innovation}

Wolff Annika, Knutas Antti, Palacin Victoria, Seidelin Cathrine, Kun Peter, Mulder Ingrid

This is a Final draft version of a publication

published by Association for Computing Machinery

in C\&T '19 Proceedings of the 9th International Conference on Communities \& Technologies Transforming Communities

DOI: $\quad 10.1145 / 3328320.3328381$

Copyright of the original publication: (C) 2019 ACM, Inc.

Please cite the publication as follows:

Annika Wolff, Antti Knutas, Victoria Palacin, Cathrine Seidelin, Peter Kun, and Ingrid Mulder. 2019. Civic Data Literacies for Bottom-up Data Innovation. In Proceedings of the 9th International Conference on Communities \& Technologies - Transforming Communities (C\&T '19). ACM, New York, NY, USA, 306-309. DOI: https://doi.org/10.1145/3328320.3328381

This is a parallel published version of an original publication. This version can differ from the original published article. 


\section{ABSTRACT}

This workshop is concerned with the potentials and barriers of data in facilitating bottom-up innovation. We focus on two specific communities that could benefit from utilizing data, but may struggle currently. Firstly, civil society participating in grassroots actions, who use public data for innovation and to strengthen their advocacy. Secondly, organisations - especially SME's - who want to make use of data especially large complex data sets, to design data-driven services.

\section{Civic Data Literacies for Bottom-up Data Innovation}

\section{Annika Wolff}

Antti Knutas

Victoria Palacin

Lappeenranta University of Technology

Lappeenranta, Finland

annika.wolff@lut.fi

antti.knutas@lut.fi

victoria.palacin@lut.fi

\section{Cathrine Seidelin}

IT University of Copenhagen

Copenhagen, Denmark

cfre@itu.dk

\author{
Peter Kun \\ Ingrid Mulder \\ Delft University of Technology \\ Delft, The Netherlands \\ p.kun@tudelft.nl \\ I.J.Mulder@tudelft.nl
}

\section{CCS CONCEPTS}

- Human-centered computing $\rightarrow \mathrm{HCI}$ theory, concepts and models.

\section{KEYWORDS}

data literacy, innovation, civic action

Permission to make digital or hard copies of part or all of this work for personal or classroom use is granted without fee provided that copies are not made or distributed for profit or commercial advantage and that copies bear this notice and the full citation on the first page. Copyrights for third-party components of this work must be honored. For all other uses, contact the owner/author(s)

CT 2019, June 3-7, 2019, Vienna, Austria

( 2019 Copyright held by the owner/author(s).

ACM ISBN 978-1-4503-7162-9/19/06.

https://doi.org/10.1145/3328320.3328381 


\section{ORGANISER BIOS}

Annika Wolff is a researcher in the field of human-data interaction. She has led work in developing and piloting new methods for teaching data literacy skills in UK primary and secondary schools and in understanding how open data can be utilized in education and for innovation. She has authored a number of papers on engaging non-experts in design with complex smart city data. Other research interests include the use of gamification and narratives to motivate human learning and in mining data sources for revealing cultural narratives across a city.

Peter Kun is a PhD candidate at TU Delft, focused on using data in the design process. With his research Peter develops the notion of "creative data work"; enabling non-specialists to leverage data as a mode of inquiry to better understand the world towards meaningful innovations. Earlier, Peter worked on the Open4Citizens CAPS project, creating a toolkit for citizens to develop data literacy and leverage open data and helped in developing better issue-oriented open data hackathons.

Cathrine Seidelin is a PhD student at the Computer Science Department at the IT University of Copenhagen, Denmark. Her research focuses on developing new methods that can help SMEs to make better use of (open) data as a design material in service innovation. She works closely with Industry to co-design such methods in collaboration with domain experts. Other research interests include the development and influence of data science in society (in particular the public sector) as well as understanding the shared and unique challenges of data science environments.

\section{WORKSHOP THEMES}

Where to date a large body of research has focused on making data open and available within these communities, there is a growing concern that use of data within such problem-solving and innovation processes can, and often do, stall.

Theories as to why this happens tend to focus on the barriers of use. Within each of these communities, the people may be considered domain experts and as such have a critical role to play in interpreting data. However, the data often still lacks context (it may be collected by others and lack vital information for making sense of it). In addition, such communities often lack the specialist expertise required to get the most value from the data $[4,5]$. Theories as to when this occurs is less clear: it is important to understand at what point in a civic action or innovation process a problem is likely to arise, especially those related to data, in order to fully understand the context and the probable cause. In this regard, initiatives that have relied on specialist support can be found impacted when the support is removed. This in turn highlights that what needs to be done is to enhance communities' capacity to undertake activities independently [1]. To understand how this should be achieved, we aim to extend prior work in overcoming barriers for non-specialist users to engage with and utilise data. We start by considering two approaches to overcoming these barriers. The first is in the building of civic data literacies, that provide non-specialist communities with the awareness and knowledge they need to ask and answer questions of concern from data and to use it as evidence for change. The second is in making data easier to access by those who lack the necessary data literacy skills, for example by providing better "interfaces" to data.

We frame community-led, bottom-up data innovation as an activity that occurs through a process of individual and participatory interpretation and sense-making from data, that provides evidence that supports the community to coalesce around a single idea, or a rally for change. Such data innovation has a focus on framing the right issue to tackle through data [3], opposed to the analytics-focus of "traditional data work". Starting from framing informs a larger option space for communities' innovation processes, such as using their advocacy in acquiring data through requesting access to open data, or setting up a citizen observatory, depending on a given context. Since this process can take unexpected turns through longer time-frames, being competent and literate in working with data and supporting an adaptive participatory sense-making process around data can enable a community to better articulate and frame their issue in focus.

In other domains we have witnessed analogue best practices to support problem-framing. Such as, the ubiquitous business model canvas has inspired organizations of all sorts to iteratively design their business plan through a boundary object that captures the key parameters around an issue.

However, when it comes to civic data literacy and bottom-up innovation with data, it is little agreed upon what cognitive aspects to support in framing a problem, which will then effectively inform 


\section{ORGANISER BIOS [CONTINUED]}

Victoria Palacin is a PhD candidate at LUT University in Finland. Her work focuses on co-creating technologies and physical data experiences with and for communities. She has designed a number of studies that seek to understand how technology design can give people agency in the development of their cities and improve the balance of powers. She is currently developing physical data experiences with communities in Boston, USA and Lappeenranta, Finland. (more about Victoria at www.mavipasi.com)

Antti Knutas is an assistant professor in the software engineering research group at the LUT University in Finland. His research interests involve the design of platforms that enable computer-supported cooperative work, more inclusive software engineering processes of digital services, and the design of communitydriven socio-technical systems from a software engineering perspective. He is currently researching how grassroots-driven civic technology groups create software.

Ingrid Mulder is an Associate Professor in Design for Social Transformation, Faculty of Industrial Design Engineering, Delft University of Technology. Her background in policy and organization sciences (MA, University of Tilburg) and behavioural sciences (Ph.D., University of Twente) reinforces her ongoing transdisciplinary research that combines strategic design with diffuse design while addressing the interplay between top-down policy and bottomup innovation. the following data work and innovation process. Developing on the notions of civic data literacy and bottom-up innovation would enable communities to decrease dependencies on specialists to operationalise on data, and to increase informed actions and general agency with data.

Building upon existing frameworks for supporting collective action $[1,2]$ and through the use of case studies, within this workshop we will deepen our understanding of the specific difficulties around how people use and make sense of data within this process and where exactly within this timeline these difficulties occur.

\section{GOALS}

The overall goals of the workshop are to 1) Better understand the realities within which bottom-up data innovation takes place, which can inform future interventions, community toolkits and frameworks for bottom-up innovation; 2) Enrich the body of case studies that capture bottom-up data innovation; 3 ) Consider multiple analytical frameworks that can be used for extracting knowledge from a variety of bottom-up data innovation case studies; 4) Synthesize different approaches and identify new avenues of research based on the identified gaps in current knowledge and research.

\section{Activities}

The activities of the workshop are grouped into three distinct phases, with different types of collaborative activity within each:

(1) Intro on civic action and bottom-up data innovation, presenting cases and lenses: Presentations - by organisers and participants. 5-minutes presentation, 2-minutes 'response' by allocated participant assigned to read the paper beforehand and pose questions and ideas.

(2) Cases and lenses - position papers unwrapped: Based on the position papers' contribution from cases and lenses (see contributions of participants, below), we will set-up group discussions where the contributed lenses can be used for analyzing the contributed cases. The organizers will also provide cases and lenses from their own work, in case of insufficient contributions. This will support understanding why bottom-up innovations are likely to fail and identify good strategies for maintaining them.

(3) Provocations: In order to understand what types of interventions should be considered for supporting communities with data, organisers will bring some of their own tools that are designed to overcome barriers to data, including data games. In groups, participants will use these to provoke discussion and new ideas and approaches to intervention based on either formal/informally building data literacies or creating civic interfaces for data. The aim is to open avenues for discussion and future research. 


\section{PUBLIC DESCRIPTION}

This workshop focuses on the potentials and barriers of data in facilitating bottom-up innovation, leading to action. We invite participants who have an interest in the mechanisms through which bottom-up actions occur and the methodologies that support them. There is a growing idea that collecting, or having access to data can empower civil society to find and solve problems and take actions that improve their lives. There is a similar notion that organisations can utilise data, either in improving their own practice or in creating value from data, such as in the design of new smart prod ucts and services. But such communities, whilst often experts in the domain, are not necessarily specialists in working with data. They may therefore encounter barriers that prevent innovation occurring, or leading to action, especially when relevant specialist support is absent, or is removed too early. This workshop will explore both when and why this is likely to happen and what can be done to overcome it.

\section{Outputs}

The output of the workshop is two-fold: to develop a research agenda and to write a collaboratively written position paper that documents the salient discussions from the workshop. For this, we will use a 'reporters from the future' approach. Accepted participants are expected to actively participate in the documentation process, for example by writing a short article of no longer than 500 words, stressing their main insights.

\section{PARTICIPANTS}

Maximum number of participants is 30 . The intended audience are $\mathrm{HCl}$ researchers, social scientists, organisational actors, civic actors and community practitioners who are interested to explore how bottom-up data innovation happens as part of civic action or innovation in organisations. For recruitment, the organisers will first create a website describing the workshop and will disseminate the call and the website text through the organisers own networks. The CfP will be also publicized through standard channels such as Twitter and Wikicfp (http://www.wikicfp.com/cfp/) as well as through subscribed mailing lists such as PDworld and ComTech.

We will seek two types of contributions as position papers: 1) Cases: Examples of bottom-up innovation projects, where civic action took place. For example, researchers working with a community to assist them in bottom-up data innovation. 2) Lenses: Conceptual frameworks, metrics or tools that can be used to assess different case studies. Many perspectives can be applied to look at civic action and bottom-up data innovation (e.g., data literacy, systemic change, ladder of participation, innovation processes - lenses that are totally different ways to assess a successful civic action project).

\section{REFERENCES}

[1] Mara Balestrini, Yvonne Rogers, Carolyn Hassan, Javi Creus, Martha King, and Paul Marshall. 2017. A city in common: a framework to orchestrate large-scale citizen engagement around urban issues. In Proceedings of the $2017 \mathrm{CHI}$ Conference on Human Factors in Computing Systems. ACM, 2282-2294.

[2] Anna De Liddo and Simon Buckingham Shum. 2013. The Evidence Hub: harnessing the collective intelligence of communities to build evidence-based knowledge. (2013).

3] Kees Dorst. 2011. The core of 'design thinking' and its application. Design studies 32, 6 (2011), 521-532.

[4] Marijn Janssen, Yannis Charalabidis, and Anneke Zuiderwijk. 2012. Benefits, adoption barriers and myths of open data and open government. Information systems management 29, 4 (2012), 258-268.

[5] Ian G Johnson, Aare Puussaar, Jennifer Manuel, and Peter Wright. 2018. Neighbourhood Data: Exploring the Role of Open Data in Locally Devolved Policymaking Processes. Proceedings of the ACM on Human-Computer Interaction 2, CSCW (2018), 83. 